\title{
METODOLOGIAS DE APRENDIZAGEM \\ DIRECIONADAS ÀS PESSOAS IDOSAS: UMA REVISÃO SISTEMÁTICA DA LITERATURA
}

\author{
Geovana Samuel Oliveira ${ }^{1}$ \\ Guilherme Henrique Koerich² \\ Maria Fernanda Baeta Neves Alonso da Costa ${ }^{3}$ \\ Michele Medeiros ${ }^{4}$
}

resumo

A educação com idosos requer uma pedagogia específica. A adequação de conteúdos e a utilização de metodologias de aprendizagens direcionados ao público idoso são fundamentais para

1 Graduanda em Enfermagem. Estagiária do Hospital Universitário Polydoro Ernani de São Thiago (HU/UFSC) vinculada ao Setor de Vigilância em Saúde e Segurança do Paciente. E-mail: contatogeovanaoliveira@gmail.com.

2 Graduado em Gastronomia e Turismo. Mestre em Engenharia e Gestão do Conhecimento. Técnico em Assuntos Educacionais no Instituto Federal de Santa Catarina (IFSC). E-mail: guilherme. koerich1@gmail.com.

3 Graduada em Enfermagem. Pós-Doutorado em Ciências da Saúde na Universidade de São Paulo (USP). Docente do Departamento de Enfermagem e do Programa de Pós-Graduação em Enfermagem (PEN), da Universidade Federal de Santa Catarina (UFSC). Coordenadora do Núcleo de Estudos da Terceira Idade (NETI/UFSC). E-mail: fernanda.baeta@ufsc.br.

4 Graduada em Enfermagem. Mestra em Gestão do Cuidado em Enfermagem. Enfermeira do Núcleo de Estudos da Terceira Idade da Universidade Federal de Santa Catarina (NETI/UFSC). E-mail: mtmedeiro@gmail.com. 
que o mesmo prospere e tenha êxito em processos educativos. $\bigcirc$ objetivo do presente artigo foi levantar metodologias de aprendizagem direcionadas às pessoas idosas na literatura nacional e internacional, no período de 2006 a 2020. Trata-se de uma revisão sistemática da literatura realizada em cinco bases de periódicos internacionais e também no Catálogo Nacional de Teses e Dissertações da CAPES. Foram identificados quatro estudos que contemplaram o objetivo proposto. Observa-se produção pouco expressiva acerca da temática, com estudos interdisciplinares e em sua maioria direcionados a aprendizagem ao longo da vida principalmente no que se refere ao desenvolvimento de habilidades digitais.

palavras-chave

Metodologias de Aprendizagem. Idoso. Revisão Sistemática.

\section{Introdução}

O envelhecimento populacional é uma das transformações sociais mais significativas do século XXI, com implicações em quase todos os setores da sociedade (UNRIC, 2019), incluindo o da educação. A aprendizagem ao longo de todo o ciclo vital é um novo paradigma, desafio e princípio organizador para os sistemas educacionais e ao processo de ensino e aprendizagem (CACHIONI et al., 2019). A expansão da sociedade do conhecimento ocorre de maneira acelerada devido às novas tecnologias da informação e comunicação (TIC), ao mesmo tempo em que aumenta a expectativa de vida da população em todo o mundo. Por um lado, o prolongamento da vida; e, por outro, são necessárias transformações profundas em torno da aprendizagem com pessoas idosas (CACHIONI et al., 2019). Neste ínterim, a aprendizagem é mediada por diferentes suportes técnicos e humanos, especialmente pelas novas tecnologias.

As TICs se referem a meios técnicos utilizados para suportar informações e auxiliar na comunicação, o qual culmina na participação social, considerando que os indivíduos possuam habilidades para uso destas ferramentas (EUROSTAT, 2016). Conforme exposto pela Comissão das Comunidades Europeias, a difusão das TIC entre a população idosa apresenta-se como uma necessidade social, visto que auxiliam os idosos na melhoria da qualidade de vida e manutenção da autonomia, além de permitir que estes se mantenham ativos na comunidade e participantes na sociedade da informação e do conhecimento (UE, 2007). 
A educação é considerada um direito fundamental. Este direito é assegurado em diferentes dispositivos de lei. A Política Nacional do Idoso traz como competências dos órgãos e entidades públicas, adequar currículos, metodologias e material didático aos programas educacionais destinados ao idoso (BRASIL, 1994). Segundo o Estatuto do Idoso, acerca da educação, os cursos poderão ofertar conteúdos relativos às técnicas de comunicação, computação e demais avanços tecnológicos, para sua integração à vida moderna (BRASIL, 2003). As instituições de educação superior ofertarão às pessoas idosas, na perspectiva da educação ao longo da vida, cursos e programas de extensão, presenciais ou à distância, constituídos por atividades formais e não formais (BRASIL, 2003). Já na Lei no 13.535, de 15 de dezembro de 2017, fica estabelecido que o poder público apoiará a criação de universidades abertas para as pessoas idosas e incentivará a publicação de livros e periódicos, de conteúdo e padrão editorial adequados ao idoso, que facilitem a leitura, considerada a natural redução da capacidade visual (BRASIL, 2017).

Pode-se observar que há vários documentos oficiais e dispositivos legais sobre a educação voltada para a pessoa idosa. No entanto, há poucos estudos publicados sobre metodologias de aprendizagem ao longo de toda a vida. Em linhas gerais, as pesquisas são voltadas para questões técnicas de desenvolvimentos ou adaptações de tecnologias e não para o processo de ensino-aprendizagem e ao uso de dispositivos tecnológicos entre idosos (CACHIONI et al., 2019). A educação com idosos requer uma pedagogia específica para que os estudantes atinjam níveis significativos de aprendizagem e desenvolvimento, para apropriação do conhecimento e o desenvolvimento de habilidades para conquistar com autonomia uma melhor qualidade de vida (LIMA, 2000). A aprendizagem possui diferentes teorias e visões no campo da epistemologia. Assim, adotamos a definição de Knud Illeris (2013), o qual define de maneira ampla aprendizagem como processo, que leva a uma mudança permanente em organismos vivos, independente do amadurecimento biológico ou ao envelhecimento. Segundo o autor, as principais áreas de estudo da aprendizagem são envolvidas pela Base (biologia, psicologia e ciência social), Condições Externas (espaço de aprendizagem, sociedade e situação objetiva), Aplicação (pedagogia e políticas de aprendizagem) e as Condições Internas (disposições, idade, situação subjetiva), no qual estes fatores estão em contínua interação entre si e com a aprendizagem (ILLERIS, 2013).

Com o olhar atento à dimensão "Aplicação", esta pesquisa tem por objetivo levantar metodologias de aprendizagem adequadas às pessoas idosas na literatura nacional e internacional. Para o alcance deste objetivo, foi realizado uma revisão sistemática na literatura, nas bases de dados Scopus, EBSCOhost, 
Web of Science, Educational Resources Information Center (ERIC) e na base nacional Scielo, assim como no Catálogo de Teses e Dissertações da CAPES (Coordenação de Aperfeiçoamento de Ensino Superior).

\section{Procedimentos metodológicos}

A pesquisa realizada é de natureza pura, e seus achados anseiam pelo avanço científico e teórico acerca das metodologias de aprendizagem direcionadas à pessoa idosa. A revisão sistemática coleta, analisa criticamente $\mathrm{e}$ sintetiza um conjunto de evidências, para responder a uma pergunta específica de pesquisa (MOHER et al., 2015). Este método de pesquisa permite maximizar o potencial de uma busca, e encontrar o maior número possível de resultados de uma maneira organizada, e minimizando tendenciosidades (COSTA; ZOLTOWSKI, 2014). Quanto ao posicionamento da pesquisa e seu objetivo, o estudo é classificado como exploratório-descritivo, sob uma abordagem predominantemente qualitativa. Dado a caracterização metodológica da pesquisa, a mesma foi desenvolvida em diferentes etapas.

A busca sistemática e a seleção das fontes bibliográficas com aplicação dos critérios de elegibilidade foram desenvolvidas em sete etapas, conforme proposto por Costa e Zoltowski (2014), a saber: 1) definição da pergunta de pesquisa, 2) escolha das bases de dados, 3) definição das palavras chave/ estratégias de busca (string), 4) busca e armazenamento dos resultados, 5) seleção pelo título, resumo e palavras-chave, de acordo com os critérios de elegibilidade (inclusão e exclusão), 6) extração dos dados, 7) análise dos documentos selecionados e 8) síntese e interpretação dos dados. Em aderência às etapas supracitadas, foi definida primeiramente a pergunta de pesquisa, que conduziu todas as etapas da mesma e consiste em investigar "quais metodologias de aprendizagem são utilizadas em ações educativas com idosos?". Na segunda etapa, foram definidas as bases de dados para a busca sistemática dos estudos. Foram selecionadas quatro bases de periódicos internacionais: 1) Scopus, 2) EBSCOhost, 3) Web of Science e 4) Educational Resources Information Center (ERIC) e na base nacional: 5) Scielo. Também foram realizadas buscas em 6) Catálogo de Teses e Dissertações da CAPES. Todas as bases foram consultadas por meio do sistema CAPES e pelo website da Biblioteca Universitária da Universidade Federal de Santa Catarina.

$\mathrm{Na}$ terceira etapa foi definido o seguinte descritor de busca (string): "“educational methodolog*" OR "methodolog* of teach" OR "teach* methodolog*" OR "learn* methodolog*") AND (elderly OR age* OR old*)", o qual foi aplicado 
respeitando as modificações necessárias de acordo com os operadores booleanos das respectivas bases de dados e de teses e dissertações. Na quarta etapa, as buscas nas bases foram realizadas no período de março a agosto de 2020 . Os resultados das buscas foram importados para o software gerenciador de referências End Note Web para aplicação dos critérios de elegibilidade.

Na quinta etapa, os documentos foram selecionados a partir da leitura do título, resumo e palavras-chave, em conformidade com os critérios de elegibilidade definidos no protocolo de revisão sistemática. Os critérios de inclusão ou exclusão dos documentos foram: quanto ao tipo de documento, foram filtrados artigos científicos em periódicos e eventos, teses e dissertações; foram incluídos documentos nos idiomas inglês, português e espanhol; quanto a área geográfica, não houve qualquer restrição a este campo; o período de publicação do conteúdo compreende os anos de 2006 a 2020, ou seja, produção dos últimos quinze (15) anos; e foram incluídos somente os documentos disponíveis para download na íntegra gratuitamente, seja pelo portal da CAPES, e demais portais e websites públicos e gratuitos.

Na etapa seis, a extração dos dados dos documentos selecionados foi realizada com o auxílio de uma planilha do pacote Microsoft Excel para apresentação dos dados bibliométricos dos estudos. Na etapa sete, a análise dos estudos ocorreu pela leitura na íntegra dos mesmos, com a realização de fichamentos dos documentos. Por fim, na última etapa, etapa oito, a síntese e interpretação dos dados serão apresentadas como resultados deste artigo na seção seguinte.

\section{Resultados}

Os resultados da revisão sistemática da literatura realizada serão apresentados e analisados em dois métodos distintos: (1) análise bibliométrica e (2) análise de conteúdo. Na análise bibliométrica, apresenta-se o processo de seleção dos documentos, o qual foi orientado por um protocolo de coleta de dados para seleção dos estudos que compõem as amostras da pesquisa. $\mathrm{Na}$ análise de conteúdo, apresentam-se as metodologias de aprendizagem para idosos sugeridas pelos autores.

\section{Análise bibliométrica}

Após a aplicação das estratégias de busca (string) e demais filtros apresentados acima nos procedimentos metodológicos, as amostras de materiais foram divididas em: Amostra 1, contemplando os artigos em periódicos e 
eventos científicos, e Amostra 2, composta por teses e dissertações. A Amostra 1 compreende um total de 1953 artigos científicos. Sendo que quinhentos e quarenta (540) foram importados da base Scopus, setecentos e oitenta e três (783) da EBSCOhost, quinhentos e trinta e sete (537) da Web of Science, noventa e três (93) da ERIC e nenhum documento foi encontrado na base Scielo. A Amostra 2 é composta inicialmente por 25 documentos importados do Catálogo de Teses de Dissertações da CAPES. Os arquivos correspondentes a Amostra 1 foram importados para o software gerenciador de bibliografias End Note Web. Já os arquivos da Amostra 2 foram gerenciados em planilhas do Microsoft Excel. O processo de filtragem e exclusão dos documentos repetidos, assim como a aplicação dos critérios de elegibilidade (inclusão e exclusão), podem ser conferidos no fluxograma da Figura 1.

Figura 1 - Fluxograma da busca na literatura e seleção dos estudos.

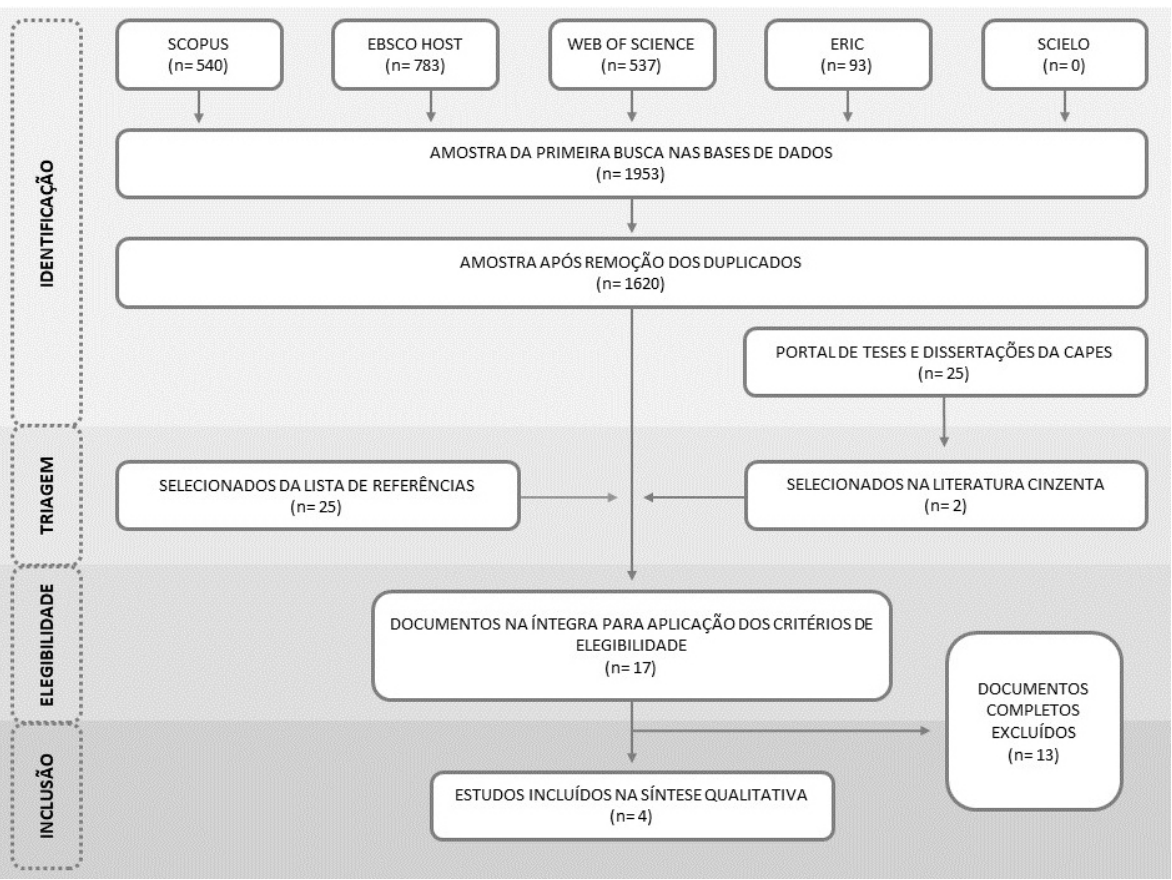

Fonte: Adaptado de Moher et al. (2010).

Na Amostra 1, foram selecionados três (3) documentos para leitura na íntegra e composição da amostra final, conforme apresentados no Quadro 1: 
Quadro 1 - Artigos selecionados na Amostra 1.

\begin{tabular}{|l|l|l|l|}
\hline Autor (Ano) & Título & $\begin{array}{l}\text { Metodologia de } \\
\text { aprendizagem }\end{array}$ & Objetivo do estudo \\
\hline $\begin{array}{l}\text { Martorell et al. } \\
\text { (2009) }\end{array}$ & $\begin{array}{l}\text { Inquiry-Based Learning } \\
\text { for Older People at a } \\
\text { University in Spain }\end{array}$ & $\begin{array}{l}\text { Aprendizagem } \\
\text { baseada em investi- } \\
\text { gação (Inquiry-Based } \\
\text { Learning - IBL) }\end{array}$ & $\begin{array}{l}\text { Descrever a imple- } \\
\text { mentação e avaliação } \\
\text { de metodologia instru- } \\
\text { cional para o ensino } \\
\text { de ciências a pessoas } \\
\text { idosas. }\end{array}$ \\
\hline $\begin{array}{l}\text { González, } \\
\text { Gómez-Millán, } \\
\text { Rubio (2017) }\end{array}$ & $\begin{array}{l}\text { Competencias comu- } \\
\text { nicativas mediadas } \\
\text { em estudiantes } \\
\text { universitários mayores. } \\
\text { Alfabetización tecnoló- } \\
\text { gica como experiência } \\
\text { inovadora. }\end{array}$ & $\begin{array}{l}\text { Aprendizagem } \\
\text { baseada em } \\
\text { problemas. }\end{array}$ & $\begin{array}{l}\text { Descrever a expe- } \\
\text { riência de treinamento } \\
\text { em habilidades de } \\
\text { alfabetização digital } \\
\text { com o uso da apren- } \\
\text { dizagem baseada em } \\
\text { problemas e avaliação } \\
\text { por rubrica. }\end{array}$ \\
\hline $\begin{array}{l}\text { Cachioni et al. } \\
\text { (2019) }\end{array}$ & $\begin{array}{l}\text { Aprendizagem ao } \\
\text { longo de toda a vida } \\
\text { eletramento digital de } \\
\text { idosos: um modelo } \\
\text { multidisciplinar de } \\
\text { intervenção com o } \\
\text { apoio de um aplicativo. }\end{array}$ & $\begin{array}{l}\text { Experience Samplin- } \\
\text { gand Programmed } \\
\text { Intervention Method } \\
\text { (ESPIM) }\end{array}$ & $\begin{array}{l}\text { Realizar uma inter- } \\
\text { venção de alfabeti- } \\
\text { zação e letramento } \\
\text { digital para idosos com } \\
\text { duas metodologias } \\
\text { distintas, com e sem } \\
\text { utilização de aplicativo. }\end{array}$ \\
\hline
\end{tabular}

Fonte: Elaborado pelos autores.

$\mathrm{Na}$ Amostra 2, a qual compreende teses e dissertações, foi selecionada apenas uma tese de doutorado nacional para composição da amostra final, conforme disposto no Quadro 2.

Quadro 2 - Tese selecionada na Amostra 2.

\begin{tabular}{|l|l|l|l|}
\hline Autor (Ano) & Título & $\begin{array}{l}\text { Metodologia de } \\
\text { aprendizagem }\end{array}$ & Objetivo do estudo \\
\hline Sales (2007) & $\begin{array}{l}\text { Modelo multiplicador } \\
\text { utilizando a apren- } \\
\text { dizagem por pares } \\
\text { focado no idoso. }\end{array}$ & $\begin{array}{l}\text { Modelo multiplicador } \\
\text { por pares, educação } \\
\text { por projetos. }\end{array}$ & $\begin{array}{l}\text { Desenvolver um } \\
\text { modelo multiplicador } \\
\text { utilizando a apren- } \\
\text { dizagem por pares } \\
\text { focado no idoso. }\end{array}$ \\
\hline
\end{tabular}

Fonte: Elaborado pelos autores.

Os estudos selecionados são recentes (2007-2019) e pouco emergentes na literatura. Não foi observada uma produção latente da temática na literatura, assim como, ao longo do período houve espaçamento de tempo sem 
qualquer publicação acerca da temática. As pesquisas são oriundas da Espanha (MARTORELL et al., 2009; GONZÁLEZ; GÓMEZ-MILLÁN; RUBIO, 2017) e do Brasil (CACHIONI et al., 2019; SALES, 2007).

\subsection{Análise de conteúdo}

Nesta seção, foram apresentadas as principais considerações e ideias defendidas pelos autores dos trabalhos selecionados, com vistas à construção de um corpus teórico sobre as Metodologias de Aprendizagem direcionadas às Pessoas Idosas. Para isto, esta construção teve como lente teórica o disposto nos trabalhos selecionados nesta revisão sistemática da literatura. As metodologias de aprendizagem apresentadas nos estudos evidenciam quatro formas distintas com que foram estruturados cursos voltados para idosos em programas e universidades, as quais foram: a Aprendizagem Baseada em Problemas (GONZÁLEZ; GÓMEZ-MILLÁN; RUBIO, 2017), Aprendizagem Baseada em Investigação - IBL (MARTORELL et al., 2009), Aprendizagem por Pares (SALES, 2007) e o aplicativo ESPIM (Experience Sampling and Programmed Intervention Method) (CACHIONI et al., 2019). Apresentamos no quadro a seguir (Quadro 3) uma breve descrição da dinâmica das metodologias empregadas.

Quadro 3 - Descrição das metodologias de aprendizagem.

\begin{tabular}{|l|l|}
\hline Autor (Ano) & Descrição da metodologia de aprendizagem \\
\hline Martorell et al. & $\begin{array}{l}\text { Contrapõe o ensino dedutivo estimulando a aprendizagem indutiva. Neste } \\
\text { método, o instrutor apresenta um estudo de caso ou problema do quotidiano } \\
(\text { (1) definição da questão de pesquisa, para que os alunos idosos realizem } \\
\text { pesquisas científicas, desenvolvam hipóteses; (2) definição de hipóteses que } \\
\text { conduzam seus experimentos; (3) desenvolvimento de projeto experimental } \\
\text { para que os idosos sejam protagonistas do processo de aprendizagem. } \\
\text { Ainda, o instrutor tem o papel de aprendiz especialista/facilitador da aprendi- } \\
\text { zagem. Realiza-se avaliação cognitiva e da própria metodologia de ensino. }\end{array}$ \\
\hline González, \\
$\begin{array}{l}\text { Gómez-Millán, } \\
\text { Rubio (2017) }\end{array}$ & $\begin{array}{l}\text { Projetam-se situações problema onde os alunos trabalham em equipe } \\
\text { desenvolvendo a aprendizagem baseada em problemas. Antes do curso } \\
\text { desenvolve-se um momento explicativo sobre o conteúdo, a metodologia e as } \\
\text { açonais digitais e também à plataforma virtual de ensino como méo de comu- } \\
\text { nicação entre professor-aluno. Após fornecer os meios necessários, os alunos } \\
\text { possuem quatro semanas para resolver o caso proposto. Após a resolução, } \\
\text { esta deve ser apresentada ao grupo por meio de blog ou slide. A avaliação é } \\
\text { realizada por rubricas: 1) competências necessárias para determinar conteúdo } \\
\text { adquirido; 2) processo de aquisição de habilidades. }\end{array}$ \\
\hline
\end{tabular}




\begin{tabular}{|l|l|}
\hline Autor (Ano) & Descrição da metodologia de aprendizagem \\
\hline $\begin{array}{l}\text { Cachioni et al. } \\
(2019)\end{array}$ & $\begin{array}{l}\text { Conteúdos divididos em } 15 \text { encontros semanais de } 2 \text { h/aula. A apresentação } \\
\text { da aula é impressa e entregue aos alunos no início de cada aula, de modo } \\
\text { que possa ser utilizada como complemento durante as atividades síncronas } \\
\text { euxilio dos monitores). Após as aulas presenciais, os idosos são informados } \\
\text { sobre a realização de "tarefas de casa" (cinco tarefas, uma por dia) referente } \\
\text { ao conteúdo aprendido em aula. O aplicativo registra o horário, a frequência e } \\
\text { o tempo de realização de cada tarefa. }\end{array}$ \\
\hline Sales (2007) & $\begin{array}{l}\text { Após analisar a realidade da atividade proposta, desenvolve-se material didá- } \\
\text { tico adequado às necessidades dos alunos idosos como apoio às atividades } \\
\text { de ensino. Em seguida, forma-se o idosónultiplicador (por meio de facilitador) } \\
\text { observando suas características necessárias para tal papel. Este modelo deve } \\
\text { contemplar a interação, necessidades, afetividade entre os pares e a troca de } \\
\text { experiências durante o processo de ensino-aprendizagem. O idoso multipli- } \\
\text { cador, para a troca de conhecimentos, utiliza da metodologia de estratégia por } \\
\text { projetos, por meio de oficinas. Ainda é necessário garantir suporte técnico e } \\
\text { recursos físicos ao idoso facilitador. A avaliação é realizada de forma proces- } \\
\text { sual e formativa. }\end{array}$ \\
\hline
\end{tabular}

Fonte: Elaborado pelos autores.

Entre os quatro estudos selecionados, três têm sua abordagem educacional voltada ao ensino de habilidades e interações com a tecnologia e o mundo digital (GONZÁLEZ; GÓMEZ-MILLÁN; RUBIO, 2017; SALES, 2007; CACHIONI et al., 2019). O quarto estudo, de Martorell et al. (2009), segue este pressuposto, apontando que o ensino de habilidades digitais são uma temática recorrente na aprendizagem de idosos. De outro modo, o autor propõe uma aprendizagem direcionada para o desenvolvimento de habilidades científicas e a construção do conhecimento por meio de um ensino indutivo, que envolve um desafio, requerendo conhecimentos conceituais, habilidades e fatos para a aquisição da aprendizagem (MARTORELL et al., 2009).

Um ponto importante a ser considerado é que ambos os estudos envolveram construções dialógicas em sala de aula e nos trabalhos em grupo (SALES, 2007; MARTORELL et al., 2009; GONZÁLEZ; GÓMEZ-MILLÁN; RUBIO, 2017; CACHIONI et al., 2019). O apoio de tecnologia digital participou da implementação das metodologias presentes em dois estudos (GONZÁLEZ; GÓMEZ-MILLÁN; RUBIO, 2017; CACHIONI et al., 2019), demonstrando a tecnologia como importante ferramenta no processo de aprendizagem. O desenvolvimento de materiais didáticos (impresso ou digital) apropriado para o público idoso é indicado nos documentos oficiais (BRASIL, 1994; BRASIL, 2003) e foi fator relevante nos estudos analisados. No método ESPIM, o conteúdo desenvolvido 
em sala de aula era impresso e entregue aos alunos para consulta no domicílio (CACHIONI et al., 2019). Na aprendizagem por pares, houve construção de material didático para o idoso-aprendiz e para o idoso-monitor (SALES, 2007). Na aprendizagem baseada em investigação, os instrutores desenvolveram material de apoio didático para guiar as aulas práticas e um livro preparado para cada curso, considerando o ensino-aprendizagem para idosos (MARTORELL et al., 2009). González, Gómez-Millán, Rubio (2017) disponibilizaram previamente ao curso e a cada atividade mídias explicativas sobre os conteúdos, metodologias, e ações necessárias para o alcance dos objetivos da atividade, sendo todo o ensino focado na metodologia de aprendizagem baseada em problemas.

Quanto à avaliação do processo de aprendizagem, os estudos trazem que esta ocorre em momentos e formas específicas, a depender de cada um deles. O modelo de aprendizagem por pares avaliou o material didático construído junto aos idosos durante as oficinas, adequando-os para posterior utilização pelos monitores idosos e os aprendizes (SALES, 2007). A aprendizagem baseada em problemas realizou avaliação por duas rubricas que envolviam uma autoavaliação do aluno em qualquer momento durante o aprendizado e quatro avaliações do professor (duas em cada ciclo), além de avaliar o corpo docente e o método utilizado no final do curso (GONZÁLEZ; GÓMEZ-MILLÁN; RUBIO, 2017). A aprendizagem baseada em investigação aplicou avaliação nos níveis cognitivos e metodológicos do ensino, sendo que, neste último, avaliou dados demográficos dos alunos, do instrutor, do curso, do material de ensino e do método utilizado nos dois cursos do estudo (MARTORELL et al., 2009). No estudo que apresentou o método com e sem a utilização do aplicativo móvel (sistema ESPIM), não foi mencionado o uso de avaliação do processo de aprendizagem (CACHIONI et al., 2019).

A preocupação com o protagonismo do idoso no aprendizado esteve presente nos quatro estudos, sendo descrita mais especificamente em três dos selecionados: na aprendizagem baseada em problemas, o idoso evoluiu o conhecimento junto ao instrutor por meio das dúvidas e dificuldades apontadas por este idoso (GONZÁLEZ; GÓMEZ-MILLÁN; RUBIO, 2017); na aprendizagem por pares, o idoso participou da construção do material didático e foi preparado para atuar como multiplicador do conhecimento adquirido no curso (SALES, 2007); na aprendizagem baseada em investigação, os idosos eram instigados a confirmar ou refutar uma hipótese elaborada por eles frente a uma indagação, construindo os caminhos para o desenvolvimento de habilidades científicas e construção do conhecimento (MARTORELL et al., 2009). O estudo de Cachioni et al. (2019) menciona sua intervenção como estruturada 
também nas motivações e interesses de idosos frequentadores de programas de extensão das Universidades Abertas para as Pessoas Idosas.

Existem poucos relatos sobre a experiência referente à formação gerontológica daqueles que ministram conteúdos a idosos (CACHIONI et al., 2015). O conhecimento na área daqueles que ministram os cursos muitas vezes advém do trabalho em programas voltados à terceira idade, dos grupos de pesquisa ou da busca por leituras sobre a temática (CACHIONI et al., 2015). No método de aprendizagem por pares, os instrutores foram idosos preparados para tal função. Tinham que dispor de características como disposição, tempo e dedicação (SALES, 2007). O método ESPIM foi concebido e desenvolvido por meio de parcerias interdisciplinares que envolveram profissionais e pesquisadores das áreas de Gerontologia. Neste estudo, apresentam-se aulas preparadas por professores docentes da universidade e ministradas por alunos da graduação, da pós-graduação e monitores (CACHIONI et al., 2019). O estudo de González, Gómez-Millán, Rubio (2017) e Martorell et al. (2009) não mencionam a formação dos tutores/instrutores.

As principais contribuições apontadas nos estudos das metodologias empregadas pelos autores perpassam pelo protagonismo do idoso na construção do conhecimento científico e no reforço das competências e habilidades deste, sejam nas áreas das tecnologias digitais ou na busca de novos conhecimentos. Ainda é incipiente estudos que abordam metodologias de aprendizagem baseadas em perguntas ao público idoso, motivo que estimulou o desenvolvimento da pesquisa de Martorell et al. (2009); este coloca a satisfação dos alunos relacionada às expectativas sociais e cognitivas atendidas e o aprendizado de integração dos conhecimentos alcançado. Este autor ainda assinala que a metodologia baseada em investigação pode ter relevância para outros instrutores de educação para adultos. González, Gómez-Millán e Rubio (2017) concluíram que seu trabalho com idosos de Programas Universitários Seniors utilizando a aprendizagem baseada em problemas, melhorou as competências dos idosos no uso das tecnologias de informação e comunicação, exceto no uso dos "fóruns" como ferramentas de aprendizagem e discussões. $\mathrm{O}$ autor avaliou também que o grau de satisfação dos alunos com ferramentas de comunicação síncronas e assíncronas variou, aumentando conforme proximidade de contato com o professor. Este demonstrou eficácia das metodologias de aprendizagem baseadas em problemas e avaliação com rubricas, neste treinamento. Cachioni et al. (2019) apontam expectativas de identificar diferenças entre aprendizagem e desempenho do idoso no uso de dispositivos móveis; que o aplicativo auxilie na aquisição de conhecimento, senso de autoeficácia e habilidades digitais. Sales (2007) aponta como contribuições da sua tese a 
emersão da temática de inclusão digital para idosos apoiada na metodologia por pares, de cunho original; a reflexão andragógica, destacando a importância da interação, experiência, necessidades e interesses, e ambiente afetivo na aprendizagem de idosos; os materiais didático-pedagógicos desenvolvidos que subsidiaram a escrita do livro "Informática para a Terceira Idade", sendo que seu material primou por contornar barreiras da linguagem e visuais, bem como levou em consideração os declínios cognitivos, adequando linguística e a cultura dos aprendizes; caracterizou esse idoso multiplicador como alguém que tem um laser cognitivo, computador em casa, grau de escolaridade acima do fundamental e/ou interesse no voluntariado. Por fim, a autora assinala as contribuições científicas deixadas foram cinco artigos, um livro e uma comunicação oral em evento científico.

As limitações nos estudos apontadas pelos autores foram: a falta de avaliação prévia acerca da motivação dos alunos com o que tem interferido para o aprendizado de competências digitais, sendo considerado este um fator determinante na adesão de metodologias de aprendizagem participativas (GONZÁLEZ; GÓMEZ-MILLÁN; RUBIO, 2017). Martorell et al. (2009) trouxeram como limitações o número reduzido da amostra e o fato desta ser geograficamente limitada, visto que todos os participantes moravam em um raio de 10 milhas do local de desenvolvimento do estudo. Cachioni et al. (2019) não apontaram limitações no artigo selecionado. Sales (2007) apontou como limitações o fato de sua população ser de idosos que apresentavam somente declínios considerados normais ao processo de envelhecimento, o fato de todos morarem em Florianópolis, terem média de 64 anos, serem alfabetizados e na maioria mulheres; a necessidade de avaliação processual, gradual e contínua durante todo o desenvolvimento também foi apontada.

\section{Discussões}

Os quatro estudos que compõem a amostra final desta pesquisa retratam o uso de metodologias distintas na aprendizagem com pessoas idosas. Em um dos estudos desta pesquisa, foi realizada uma intervenção educativa às pessoas idosas com o objetivo de oportunizar a alfabetização e letramento digital no uso de dispositivos móveis. A UNESCO tem desempenhado papel pioneiro na defesa da educação de adultos e na promoção de uma abordagem global de aprendizagem ao longo da vida (CACHIONI et al., 2019). Na atualidade, o conhecimento tem se expandido de maneira acelerada e as pessoas idosas, cada vez mais, precisarão aprender a utilizar tecnologias da informação e 
comunicação; em especial, os dispositivos móveis com aplicativos, no seu cotidiano. Esta prática oferece oportunidades para a alfabetização e letramento digital no uso de tablets e smartphones.

O letramento digital implica em saber acessar as informações, coletá-las em um ambiente virtual ou digital; gerenciar informações para utilizá-las no futuro; avaliar, integrar e interpretar informações; comunicar e transmitir informações através de meios apropriados. As pessoas idosas experimentam a facilidade de acessibilidade para diversas atividades do cotidiano e incremento da própria qualidade de vida. Com os acessos na $W e b$, podem utilizar serviços bancários, efetuar compras, estabelecer e/ou ampliar as redes sociais e facilitar a sua comunicação (CACHIONI et al., 2019). Neste ínterim, o Núcleo de Estudos da Terceira Idade (NETI), Programa vinculado à Pró-reitoria de Extensão da Universidade Federal de Santa Catarina (UFSC), proporciona atividades de extensão de natureza não formal com o objetivo de proporcionar o letramento digital e o compartilhamento de informações por meio de tecnologias de informação e comunicação, com vistas à troca de conhecimento e divulgação de informações relevantes à aprendizagem ao longo da vida.

Outro estudo encontrado nesta revisão foi realizado em um Programa para Idosos na Universidade de Lleida, na Espanha, que utilizou a aprendizagem baseada em investigação (IBL). Este método aprimora as habilidades dos alunos envolvendo-os em estudos práticos de objetos do cotidiano, aumentando a curiosidade e entusiasmo pelo processo de aprendizagem. A aprendizagem ocorre por meio de perguntas que mobilizam as pessoas idosas a realizarem a pesquisa em busca das respostas (MARTORELL et al., 2009). Um dos desafios do professor é integrar o ambiente de ensino e aprendizagem e ajudar os alunos a fazerem conexões entre os tópicos complexos estudados em sala de aula e suas aplicações na vida diária. São utilizados vários recursos didáticos, como: desenhos animados para ilustrar tópicos concretos e promover um ambiente descontraído; sites para introduzir a Internet; esquemas e tabelas técnicas para compilar informações; imagens para ajudar os alunos a estabelecer conexões entre conceitos teóricos e o mundo real; diferentes tipos de gráficos (gráficos de dispersão, gráficos de linhas, gráficos de barras, gráficos de colunas, gráficos de pizza e gráficos de pirâmide); apresentações em PowerPoint nas sessões teóricas, com o tipo fontes fáceis de ler, coloridas e de tamanho grande, em ordem para minimizar as dificuldades visuais frequentemente encontradas pelos idosos (MARTORELL et al., 2009).

Embora a maioria dos estudos tenha demonstrado a eficácia do IBL, pouca pesquisa em literatura pode ser encontrada na implementação e avaliação do IBL como uma metodologia de aprendizagem com pessoas idosas. 
Um terceiro estudo realizado em Sevilha, na Espanha, descreve o desenvolvimento de competências para a alfabetização digital mediante aprendizagem colaborativa que utilizou como metodologia, a aprendizagem baseada em problemas (GONZÁLEZ; GÓMEZ-MILLÁN; RUBIO, 2017). O avanço das novas tecnologias e das redes sociais tem marcado o desenvolvimento das últimas décadas de maneira que, qualquer aspecto mundial e global é acessível. A internet e o uso das redes sociais (Facebook, Twitter, Instagram, WhatsApp, etc.) se converteram em uma peça chave para a vida social, abrindo um campo amplo de possibilidades. No entanto, para as pessoas idosas, os recursos tecnológicos parecem ser mais limitados do que para os jovens, podendo levar à exclusão e isolamento social. A integração social que os idosos desejam quando participam de redes sociais, os mantêm comunicativos, ativos e em constante aprendizagem (GONZÁLEZ; GÓMEZ-MILLÁN; RUBIO, 2017).

As instituições universitárias deveriam ofertar um modelo de ensino digital e a formação em redes sociais e sistemas informatizados. São objetivos da ONU desenvolver várias iniciativas que fomentem a acessibilidade e competências digitais básicas para garantir a participação na sociedade da informação e coesão social. A aprendizagem por competência nos Programas das Universidades da Terceira Idade deve guiar-se pelos mesmos princípios que regem o espaço Europeu de Educação Superior, ou seja, a implementação de metodologias de ensino que permitam o trabalho em equipe; estudos de casos; aprendizagem baseada em problemas e a investigação de campo (GONZÁLEZ; GÓMEZ-MILLÁN; RUBIO, 2017). Para a aquisição e desenvolvimento de competências digitais, foram desenhadas situações-problema, em que os grupos de trabalho dispunham de quatro semanas para preparar e apresentar a resolução do problema mediante Wiki ou blog, PowerPoint ou Prezi, vídeo ou fórum de discussão. Investigações prévias já validaram a metodologia aprendizagem baseada em evidências como sistema eficaz para a aprendizagem de competências. A comunicação interpessoal é um elemento chave do processo ensino-aprendizagem. Também é necessário sinalizar algumas limitações como, a falta de avaliação acerca da motivação dos estudantes (GONZÁLEZ; GÓMEZ-MILLÁN; RUBIO, 2017).

Por fim, o último estudo, uma tese de doutorado, mostrou que a aprendizagem por pares tem sido a base de programas direcionados para as pessoas idosas e se diferenciam de outros programas de educação para adultos porque as atividades são organizadas e lideradas por voluntários. Programas de aprendizagem por pares podem ser usados para tornar as formas tradicionais educacionais muito mais poderosas e incentivam os colegas a compartilharem feedback, materiais e a se apoiarem, expandindo, aprofundando e enriquecendo 
as formas tradicionais de ensino-aprendizagem (SALES, 2007). A autora da tese propõe o desenvolvimento de um modelo multiplicador utilizando o programa de aprendizagem por pares. O multiplicador é considerado o "professor-aluno", que assume papéis de ação juntos aos seus colegas, possibilitando que eles também reflitam sobre sua prática de forma sistemática. Nesse sentido, o multiplicador configura-se como o responsável pela transmissão do conteúdo aprendido a outros, de forma a disseminar o conhecimento por ele adquirido na formação. Esse modelo fundamenta-se em um processo participatório de inclusão social e digital (SALES, 2007).

O modelo multiplicador por pares está estruturado em quatro processos principais: abordagem educacional, objetivos, conteúdo e metodologia de ensino. A base educacional do modelo é a orientação teórica de Paulo Freire e os princípios da andragogia dos quais se consideram: interação, afetividade, necessidades e interesses e experiências. A seguir, segue de forma esquemática, o modelo multiplicador por pares. A pesquisa da tese foi proposta e desenvolvida no Núcleo de Estudos da Terceira Idade (NETI/PROEX/UFSC), uma vez que, os estudantes idosos demonstraram-se interessados em conhecer informática e internet. Assim, em março de 2003 iniciou-se o projeto de extensão intitulado "Oficinas de internet para terceira idade", no Departamento de Informática e Estatística da UFSC, que atendeu cerca de 10 idosos por semestre. Durante as oficinas observou-se que alguns idosos-aprendizes tomavam a iniciativa de se auxiliarem mutuamente quando percebiam que um dos colegas estava com alguma dificuldade/dúvida ou quando eram por eles solicitados. Estavam sempre prontos para atendê-los, independentemente da professora. Notou-se que, nessas ocasiões, os ajudados se sentiam mais à vontade (menos constrangidos) para tirar uma dúvida ou para resolver/ elucidar um problema referente aos conteúdos das oficinas ou no manuseio do computador, dando a nítida impressão de que havia melhor compreensão entre eles (falavam a mesma linguagem).

Como crescia a demanda de idosos pelas oficinas e faltavam voluntários para ajudar, surgiu a ideia de formar os próprios idosos para se tornarem multiplicadores, visto que alguns deles são bem mais receptíveis à ideia de um trabalho voluntário, por se sentirem úteis e exercerem a cidadania ajudando ao próximo, além de terem tempo disponível. Verificou-se que a comunicação entre pares da mesma faixa etária tornou-se uma facilidade para os aprendizes. O modelo educacional proposto é uma orientação que permite gerar atividade (dinâmicas), em função de situações diferentes, que podem ser definidas para outra situação, fim ou contexto envolvendo a aprendizagem por pares focada no idoso. Para isso, a abordagem educacional é entendida nesse modelo como a 
explicitação do processo de construção da relação entre a interação, afetividade, necessidades e interesses e experiências. Essa relação pauta-se por um trabalho que cursa num ambiente afetivo, pela importância do emocional no processo de ensino-aprendizagem do idoso, um adulto cujas experiências pretéritas precisam ser valorizadas, respeitadas e evidenciadas nesse processo educacional.

Salienta-se, também, que essa abordagem está focada em uma educação informal e inclusiva para formar idosos-multiplicadores, razão pela qual se utilizam oficinas, por serem mais flexíveis e dinâmicas e facilmente adaptáveis para atender as necessidades reais do público-alvo. Assim, propicia um ambiente favorável, em que essa informalidade favorece a interação e a colaboração entre aprendizes, multiplicadores e coordenador, estimulando e facilitando a elaboração de projetos pelos idosos.

\section{Considerações finais}

A educação com pessoas idosas requer uma pedagogia específica, com adequação de conteúdos, espaços e o uso de metodologias de aprendizagem apropriadas. Como contribuições, este artigo apresenta uma revisão da literatura acerca de metodologias de aprendizagem e identifica quatro metodologias adequadas ao público idoso. A pesquisa ainda apresenta um arranjo teórico, conceitos e considerações acerca das metodologias identificadas. Considera-se que o objetivo geral desta pesquisa, levantar metodologias de aprendizagem direcionadas às pessoas idosas na literatura nacional e internacional, foi plenamente alcançado. Os procedimentos metodológicos foram satisfatórios e imprescindíveis para o alcance do objetivo proposto. Destaca-se que, com a aplicação das buscas sistemáticas, é possível inferir que ainda há uma escassez de publicações sobre a temática.

Com os resultados obtidos, foi possível levantar quatro metodologias de aprendizagem adequadas para processos educacionais com idosos. Há diferentes metodologias de aprendizagem na literatura, no entanto, foram consideradas somente aquelas que consideram as especificidades da pessoa idosa em processos educativos. Foi observado também que há uma tendência na adaptação de metodologias de aprendizagem já utilizadas em sistemas educacionais para atender as condições dos idosos. Como oportunidades de estudos futuros, é indicado a: 1) aplicação das metodologias levantadas nesta pesquisa em contextos reais de ensino e aprendizagem; 2) adequação de outras metodologias de aprendizagem contemporâneas em processos educacionais com idosos; e 3) avaliação destas metodologias pelos estudantes idosos. 


\section{LEARNING METHODOLOGIES FOR ELDERLY PEOPLE: A SYSTEMATIC REVIEW \\ OF LITERATURE}

abstract

Education with the elderly requires a specific pedagogy. Adequacy of content and the use of learning methodologies aimed at the elderly are essential for it to prosper and succeed in educational processes. The aim of this article was to survey learning methodologies aimed at older people in national and international literature, from 2006 to 2020. This is a systematic review of the literature conducted in five international journal bases and also in the National Thesis Catalog and CAPES Dissertations. Four studies were identified that contemplated the proposed objective. There is little expressive production on the subject, with interdisciplinary studies and mostly directed at lifelong learning, especially with regard to the development of digital skills.

keywords

Learning Methodologies. Elderly. Systematic Review.

referências

BRASIL. Lei no 8842, de 4 de janeiro de 1994. Dispõe sobre a política nacional do idoso, cria o Conselho Nacional do ldoso e dá outras providências. Disponível em: http://www.planalto.gov.br/ccivil_03/leis//8842.htm. Acesso em: 15 out. 2020.

BRASIL. Lei no 10.741, de 1 de outubro de 2003. Dispõe sobre o Estatuto do Idoso e dá outras providências. Disponível em: http://www.planalto.gov.br/ccivil_03/leis/2003/ 110.741.htm. Acesso em: 19 out. 2020.

BRASIL. Lei no 13.535, de 15 de dezembro de 2017. Altera o Estatuto do Idoso para garantir a oferta de cursos e programas de extensão pelas instituições de educação superior. Disponível em: https://www.planalto.gov.br/ccivil_03/_ato2015-2018/2017/ lei//13535.htm. Acesso em: 19 out. 2020.

CACHIONI, Meire et al. Aprendizagem ao longo de toda a vida e letramento digital de idosos: um modelo multidisciplinar de intervenção com o apoio de um aplicativo. Revista Brasileira de Ciências do Envelhecimento Humano, v. 16, n. 1, p. 18-24, 2019. Disponível em: http://seer.upf.br/index.php/rbceh/article/view/9751.http://seer.upf. br/index.php/rbceh/article/view/9751 Acesso em: 11 dez. 2020. DOl: http://dx.dol. org/10.5335/rbceh.v16i1.9751.

$\mathrm{CACHIONI}$, Meire et al. Metodologias e Estratégias Pedagógicas utilizadas por Educadores de uma Universidade Aberta à Terceira Idade. Educação \& Realidade, Porto Alegre, v. 40, n. 1, p. 81-103, jan./mar. 2015. Disponível em: https://www.scielo.br/j/ edreal/a/rnkWvrrHNGM5j6sMc3sHLzm/?lang=pt. Acesso em: 14 dez. 2020. DOl: https://doi.org/10.1590/2175-623645741. 

de revisão sistemática. In: KOLLER, Sílvia H.; DE PAULA COUTO, Maria Clara P.; VON HOHENDORFF, Jean. Manual de produção científica. Porto Alegre: Penso Editora, 2014, p. 55-70

EUROSTAT (Eurostat Statistics Explained). Category: Digital economy and society glossary. 2016. Disponível em: https://ec.europa.eu/eurostat/statistics-explained/index. php/Category:Digital_economy_and_society_glossary. Acesso em: 10 mar. 2021.

GONZÁLEZ, Alfonso Javier García; GÓMEZ-MILLÁN, María Rocío Bohórquez; RUBIO, Laura Rubio. Competencias comunicativas mediadas en estudiantes universitarios mayores. Alfabetización tecnológica como experiencia innovadora. Revista Latinoamericana de Tecnología Educativa - RELATEC, Espanha, v. 16, n. 1, p. 67-77, 2017. Disponível em: https://relatec.unex.es/article/view/2821. Acesso em: 11 dez. 2020. DOl: http://dx.doi.org/10.17398/1695-288x.16.1.67.

ILLERIS, Knud. Uma compreensão abrangente sobre a aprendizagem humana. In: ILLERIS, Knud (org.). Teorias contemporâneas da aprendizagem. Porto Alegre: Penso, 2013. p. 15-30.

LIMA, Mariúza Pelloso. Gerontologia educacional: Uma pedagogia específica para idosos uma nova concepção de velhice. São Paulo: Terra, 2000.

MARTORELL, Ingrid et al. Inquiry-Based Learning for Older People at a University in Spain. Educational Gerontology, Inglaterra, v. 35, n. 8, p. 712-731, jul. 2009. Disponível em: https://www.tandfonline.com/doi/abs/10.1080/03601270802708434. Acesso em: 11 dez. 2020. DOl: http://dx.doi.org/10.1080/03601270802708434.

MOHER, David et al. Preferred reporting items for systematic review and meta-analysis protocols (PRISMA-P) 2015 statement. Systematic reviews, v. 4, n. 1, p. 1-9, jan. 2015. Disponível em: https://systematicreviewsjournal.biomedcentral.com/ articles/10.1186/2046-4053-4-1. Acesso em: 29 out. 2020.

MOHER, David et al. Preferred reporting items for systematic reviews and meta-analyses: the PRISMA statement. International Journal of Surgery, Índia, v. 8, n. 5, p. 336-341, 2010. Disponivel em: https://www.sciencedirect.com/science/article/pii/ S1743919110000403. Acesso em: 17 nov. 2020.

SALES, Marcia de Barros. Modelo multiplicador utilizando a aprendizagem por pares focado no idoso. 2007. 138 f. Tese (Doutorado em Engenharia e Gestão do Conhecimento) - Centro Tecnológico, Universidade Federal de Santa Catarina, Florianópolis. 2007.

UE (Comissão das Comunidades Europeias). Envelhecer bem na sociedade da informação - uma iniciativa i2010, Plano de Acção no domínio. Bruxelas. 2007. Disponível em: https://eur-lex.europa.eu/legal-content/PT/TXT/PDF/?uri=CELEX:52007DC0332 \&from=pt. Acesso em: 10 mar. 2021.

UNRIC. CENTRO REGIONAL DE INFORMAÇÃO DAS NAÇÕES UNIDAS. Envelhecimento. Jul. 2019. Disponível em: https://unric.org/pt/envelhecimento/. Acesso em: 15 mar. 2021.

Data de Submissão: 29/12/2020

Data de Aprovação: 22/03/2021 